\title{
OBSERVATIONS ON THE GEOGRAPHICAL AND ETHNOLOGICAL DISTRIBUTION OF HOOKWORMS'.
}

\author{
By SAMUEL T. DARLING, \\ Professor of Hygiene, Faculdade de Medicina e Cirurgia \\ de São Paulo, Brazil.
}

DURING the course of investigations, primarily directed to a study of the effects of hookworm infection on people in different parts of the tropics, I have been struck with the peculiar geographical and racial distribution of the two common species of hookworms infecting man, and with its bearing on certain ethnological problems.

The observations I have made, in so far as they are related to anthropological questions, are as follows: The races of mankind, living in tropical and subtropical regions, are infested with one or more species of hookworms. In the migrations of these peoples the immigrants have carried their peculiar species of hookworms into regions occupied by people having a different worm-species-content, and by an examination of the intestinal worms of a people, the geographical and ethnic origin of their hosts can, within certain limits, be divined. I refer particularly to migrations within $35^{\circ} \mathrm{N}$. and $30^{\circ} \mathrm{S}$. latitudes, for when migrations are made into colder climates the hookworm infection is ultimately lost through inability of the embryos to persist during the phase of their life cycle spent in the soil.

There exists the deepest ignorance in regard to the migrations of people that have taken place in prehistoric times and also in regard to those within historic times where no records have been left.

But at present, in tropical countries, certain movements of populations are going on in response to a demand for agricultural labourers.

Large numbers of Tamils and Malabaris have been recruited to Malaya to work on rubber estates. Thousands of Chinese go annually to the same country to work in the tin mines. A great many North Indians from Calcutta are being employed under indenture in Fiji and British Guiana on cane and rice plantations, there is a Javanese colony in Dutch Guiana. Japanese are colonizing in the State of São Paulo, Brazil.

The origin and movements of these people are well known. They have brought enormous numbers of hookworms into the countries where they are employed. A study of the worms expelled from these people as well as those

1 This work for the most part was done under the auspices of the British Colonial Office and with the support of the Rookefeller Foundation. 
expelled from the autochthones in the countries in question discloses some. interesting facts.

Taking the island of Viti Levu, the autochthones show almost a pure infection with one species of worm, Necator americanus. No specimens of Agchylostoma duodenale were encountered in Fijians except among those that had lived in towns, or near plantations occupied by East Indians.

Among indentured East Indian coolies from Calcutta $21.4 \%$ of the worms expelled were $A$. duodenale, the rest were $N$. americanus.

Wherever Fijians were living near East Indians, they were found to have become infected with $A$. duodenale, derived from the latter race.

Infection by $A$. duodenale is becoming widespread among town-dwelling Fijians.

After East Indians have lived in Fiji for 10 to 15 years or more they lose a good many of their $A$. duodenale and disclose a relatively larger proportion of $N$. americanus.

In Malaya the Malays were found to harbour nearly a pure culture of $N$. americanus, for $98.99 \%$ of their worms were of this species, the remainder being $A$. duodenale and $A$. ceylanicum. This may be considered the formula of the country. Chinese coolies coming in to Malaya bring a worm formula of 35 to $85 \% A$. duodenale, the remainder being $N$. americanus. However, among the generation of Chinese born in Malaya-Straits born Chinese, who have often taken up Malay customs-eating with their fingers, etc., and who may have dropped Chinese customs and associates to a greater or less extent, it was remarkable to find that they had dropped also the Chinese worm formula as well, and taken up one like that of the people of the country. At the same time the influx of Chinese coolies with their large ancylostome index is gradually adding an increasing number of hookworms of this species to the common species of the natives of the peninsula.

The effect of migration into a country whose people have a different index from that of the immigrants, is to make the immigrant take on the worm index of the autochthones, while the index of the latter is more or less modified by the implantation of the worm species of the immigrant.

This was very clearly shown in Fiji.

The autochthonous population as represented by the people of Nasoqo, a remote and inaccessible interior mountain village, were found to be infected with $N$. americanus (six specimens of $A$. ceylanicum were encountered). Not a single specimen of $A$. duodenale was taken. The ancylostome index of the autochthones then must be considered as nil.

In the villages near Nausori where the autochthones are exposed to infection from soil polluted by East Indians, they were found to be harbouring some A. duodenale. Thus ten Fijians treated, were found to have 1309 hookworms of which 1246 were $N$. americanus and $63 \mathrm{~A}$. duodenale (there were six dogworms $A$. ceylanicum).

The ancylostome index of these town-dwelling Fijians was $4.8 \%$ and 
represents infection derived from North Indian sources, for the ancylostome index of the Calcutta men was 27, while that of uncontaminated Fijians was nil.

Here we are to observe two tendencies. First: a tendency for the stranger to part with some of his worms and to acquire a worm formula like that of the natives. Second a tendency for the natives to acquire certain worms from the strangers and thus modify the primitive formula of the region or race. This is actually taking place in Malaya, Fiji, Guiana and Brazil. Changes analogous to these that are taking place under our very eyes, may be assumed to have taken place centuries ago among other peoples, and if among a people to-day whose worm formula is $99 \%$ Necator we encounter a group who are harbouring $15 \% A$. duodenale or any notable number of that species we are entitled to assume that the hookworms of the latter people are derived from an alien stock.

The hookworms encountered in man are:

Agchylostoma duodenale.
$" \quad$ ceylanicum.
$" \quad$ braziliense.

These worms probably all have identical life cycles. A. duodenale and $N$. americanus $^{1}$ are obligate parasites for man, as they are not found in any of the animals.

A. ceylanicum and the less known A. braziliense are commonly found in dogs in certain tropical lands particularly in the Old World.

The adult sexually differentiated worms live in the small intestine and the females produce many ova which pass out in the faeces.

Embryos from the ova-infected faeces develop in the soil under suitable atmospheric conditions of warmth, moisture and oxygen.

The embryos penetrate the skin of the feet of people visiting polluted places and after traversing the skin, venous blood channels, right heart, lung and trachea, they reach the intestinal tract where they take up lodgement in the lumen of the small intestines, holding on to the mucous membrane by their strong armed mouths, and remaining in the host as long as seven or eight years.

While in general it has been recognized that two species chiefly were to be found in man, no survey has been made of the species actually harboured by the different races of mankind or by the inhabitants of different zones, regions or localities.

The reasons are obvious. Anti-hookworm campaigns are of very recent date and the doctor in charge is usually concerned merely in. ridding the patient of worms and ameliorating his physical condition.

The washing of faeces after employing a vermicide, and the culling and counting of thousands of worms under field conditions is not an easy or enticing vocation.

1 Necator americanus has been found in a gorilla by Leiper and Looss. 
Rarely however it has happened that the careful counting of hookworms expelled from a large number of people was necessary to the elucidation of some intensely interesting and very important medical and public health problems. Such problems were presented to me and my colleagues, Doctors M. B. Barber, H. P. Hacker, M. B. Barnes and W. G. Smillie. In the prosecution of our work the drudgery of the task was alleviated by the extraordinary interest aroused as the solution of the problems appeared to present themselves.

\section{DISTRIBUTION OF AGCHYLOSTOMA DUODENALW.}

A. duodenale is distributed to all those countries lying in Eurasia, south of $35^{\circ} \mathrm{N}$. latitude and north of $20^{\circ} \mathrm{N}$. latitude. In Europe, as in Cornish mines and in Mediterranean countries and Egypt, it may be the sole species found; nearer the Tropic of Cancer it is associated with increasing numbers of $N$. americanus. In warm mines the worm may be found farther north than $35^{\circ} \mathrm{N}$.

This species has been introduced into the American continent and the Antilles in historic times by coolies from India and Java, by Mediterranean and Levantine people into Brazil and other parts of North, Central and South America, and by Japanese and Chinese.

It has been introduced into Fiji by Indian coolies, and into Polynesia, the Philippines, and Australia, by Chinese, Japanese and Portuguese. In Europe it has been encountered in Italy, Sicily, Sardinia, Spain, Austria, Hungary, Serbia and Bulgaria. Farther north it is common among miners as in Cornwall, Belgium, Liège, Mons and Charleroi. In France it occur's in the Loire Basin, also in the mines of Germany, Poland and Silesia. Severe infections are encountered in Egypt.

While in general the species $A$. duodenale is distributed in the cooler latitudes north of $20^{\circ} \mathrm{N}$. latitude, there seems to be no reason other than the lack of opportunities for implantation, for its relative absence in equatorial regions.

Its absence is only relative for I encountered large numbers of this species in Java and Malaya among people who acquired the infection within $3^{\circ} \mathrm{N}$. and $8^{\circ} \mathrm{S}$. latitudes. It is evident therefore that there is nothing in an equatorial climate inimical to the development of the species in the soil and that the incidence of each species is purely a matter of implantation on soil equally favourable to each.

\section{DISTRIBUTION OF NECATOR AMERICANUS.}

This species is found in largest proportion in Eurasia, Africa, Indonesia and Polynesia, south of $20^{\circ} \mathrm{N}$. latitude.

In regions near the tropic of Cancer it is associated with $A$. duodenale but farther south, as in parts of Indonesia, Fiji and South Africa, it is encountered alone. 
This species has been introduced into America within historic times by Kaffir slaves from Africa and to a certain extent by the East Indian coolies from British India and Java. It is the species most commonly found in America and has been spread from Virginia to Argentina.

It is possible that either or both species have also been introduced into the American Continent from Asia, Indonesia or Polynesia by voyagers or stormtossed fishermen. This is an enticing subject for future research.

The American Continent may have been peopled $(a)$ from Asia by way of Behring Straits, $(b)$ from Asia or Indonesia across the Pacific, or $(c)^{1}$ from Polynesia across the Pacific.

In the case of $(a)$ cold would prevent the continuance of infection and the migrants would arrive free from hookworm, unless of course the average temperature of the Straits during migration was equal to that of North Carolina at the present time, for the latter temperature is the northern limit of autochthonous hookworm infection in America. In the case of $(b)$ we might expect to find either or both $A$. duodenale and $N$. americanus among the Amerinds or in such representatives of them as may have descended from (b). In the case of $(c)$ we would expect to find only $N$. americanus.

A survey of the species of hookworms harboured by Amerinds unexposed to infection from other sources, is urgently required to clear up some of these points.

In Panama the population composed of Meztizos and Zambos was found to be almost exclusively infested with $N$. americanus which may have been derived in the first instance from Negroes.

The reports of the Field Director of the International Health Board working in Central America show that the Indian (Amerind) population is infested with hookworms but the observations have been carried out in localities and among Indians who have been living in an environment contaminated with excreta of Negroes and East Indians which contain embryos of both Necator and Agchylostoma.

It will be necessary to search for tribes in inaccessible and remote places when it is desired to ascertain the primitive worm species index of uncontaminated Indians (Amerinds).

\section{GEOGRAPHICAL AND RACIAL DISTRIBUTION OF HOOKWORMS.}

\section{America.}

The species of hookworms encountered in the Southern States according to $\mathrm{Dr}$ Stiles is $N$. americanus, this was derived no doubt from the introduction of negro slaves from Africa.

${ }^{1}$ Cowan (1910), The Maoris of New Zealand, Christchurch, N.Z., records that in 1909 a Chinese fishing junk picked up off the island of Chu San a party of three South Sea Islanders who were adrift in a canoe, they had mother of-pearl shell fish-hooks and other South Sea fishing tackle with them, and had been blown and drifted fully 2000 miles from a German possession in the Western Pacific. 
No survey of the hookworms of North American Indians has yet been made. It is extremely important that this be undertaken without delay.

\section{Panama.}

In Panama there were two types of infection: $(a)$ pure infections of $N$. americanus encountered among the Panamans and probably derived from African negro sources, (b) mixed infections in which both $A$. duodenale and $N$. americanus were found. This type of infection occurred chiefly among West Indians who had been exposed to infection in their native islands from East Indian coolie sources. But it also occurred to a slight extent among natives of Panama who had been exposed to infection from West Indian negroes resident in the Canal Zone since the commencement of canal operations.

\section{BraziL. State of São Paulo.}

The species most commonly found is $N$. americanus but the proportion of Agchylostoma to Necator varies in different communities depending on circumstances.

At Itatiaia, in a former coffee plantation where many African negro slaves were worked years ago, the ancylostome index is 1.5.

At Rezende, which was formerly a detention and distribution centre for Italian, Portuguese and Spanish agricultural colonists, the ancylostome index as we might expect is much higher, 11.2, and is evidently due to the seeding of the soil with $A$. duodenale by Mediterranean people.

At Brodowski the high ancylostome index of the Japanese is being markedly altered by residence among the native Brazilian agriculturists who are so heavily infested with $N$. americanus.

Nothing has as yet been done to determine the species formula of the aborigines of South America.

Great care must be exercised in selecting tribes who live in inaccessible regions unvisited by foreigners. It should not be hard to do this in the interior of the continent or in Andean villages.

\section{EUROPE.}

The species encountered in Europe is $A$. duodenale except in those immigrants returned from Brazil or the United States.

The hookworm found infecting Cornish miners was A. duodenale (Boycott).

Isola (1904) examined 11,000 specimens collected by Parona from upper Italy and all were $A$. duodenale.

Northern Africa.

AFrICA.

The species found in Egypt and Northern Africa appears to be exclusively $A$. duodenale for this was the sole species encountered in the large mass of material passed under review by Looss in Egypt. 
Equatorial and South Africa.

In a number of autopsies I performed in Johannesburg on Kaffirs from Mozambique, the only species encountered was $N$. americanus.

Leiper, Looss and Fülleborn found this species in South Africa and among Pygmies in the Cameroons, respectively.

The Kaffirs ${ }^{1}$ appear to be parasitized exclusively by this species. The introduction of slaves from Mozambique infested with Necator will account for the exclusive presence of this species in the Southern States of America.

\section{ASIA-INDONESIA.}

Malays. The natives of the Malay Peninsula.

The Malays live in kampongs or native villages usually occupied solely by individuals of their own race. This was particularly true of the two kampongs near Kuala Lumpur where we obtained some data.

Thirty-eight boys from Kampong Malacca yielded 2262 hookworms of which 2257 were $N$. americanus, and 5 were ancylostomes, $3 A$. duodenale and 2 A. ceylanicum.

In Ulu Gombak 39 boys yielded 1559 hookworms, 1546 of these were $N$. americanus and 13 ancylostomes, of these 7 were $A$. duodenale and 6 A. ceylanicum.

Thus the percentage of ancylostomes present in the Malay kampong boys was 0.22 and 0.8 respectively.

Taking the two groups of 77 boys as a whole as representative of what the Malay worm formula should be and considering Necator and $A$. duodenale only, there were 3813 worms of which 10 only were $A$. duodenale, or an A. duodenale index or percentage of $0 \cdot 26$.

Adult Malays. Adults from their occupations are often brought into contact with Chinese of which there are large numbers in the peninsula and they have more opportunities for becoming infested with the hookworms of the Chinese, who, as it will be shown, harbour very large numbers of $A$. duodenale. We may expect the adult Malays to-day therefore to show some evidences of contamination from Chinese sources.

Sixteen adult Malays were found to harbour 1138 hookworms of which 10 were $A$. duodenale and the remainder $N$. americanus, the $A$. duodenale index being $0 \cdot 9$. Thus we see that the autochthonous Malay population of the Malay Peninsula harbours nearly a pure culture of $N$. americanus.

Malays of the Island of Java.

Among the natives of Java there was encountered a very distinct difference between the ancylostome index of the people of West Java and that of people

1 A. duodenale unquestionably is a more malignant hookworm than Necator, It is possible that some of the alleged immunity of the negro to the effects of hookworm infection is due to the fact that Kaffirs and their descendants are very largely parasitized by Necator and not by $A$. duo. denale. 
living east of the Tji Manoek river, this difference corresponds with a difference in the ethnic stocks in the two regions.

Worm counts were carried out among Malays in four kampongs in the city of Batavia (West Java): a total of 2935 hookworms were obtained from 92 people of which only 26 were $A$. duodenale, the remainder being $N$. americanus; the percentage of ancylostomes therefore was 0.88 a figure corresponding closely with that of the Malays of the Malay Peninsula.

In the mountainous region of the Preanger (West Java) there was an absence of $A$. duodenale which was very striking indeed.

Twenty-five Malays (Sudanese) in the dessa. or village of Endil Tjhoeavglaagte were found to be harbouring 1275 hookworms, and of these two were $A$..ceylanicum (derived from dogs), the rest being $N$. americanus.

In the dessa of Tjimatjam, at an elevation of 3600 feet, near the volcano Gedeh, where there was a minimum pollution of soil and of the water courses, 25 persons yielded only 150 hookworms all $N$. americanus.

In these two dessas in the Preanger the $A$. duodenale index was nil.

This absence of $A$. duodenale among 50 representative Malays in the Preanger, indicates in the most striking way that the hookworm common and proper to the people of West $\mathrm{Java}$ is $N$. americanus and that $A$. duodenale when found represents an extraneous infestation from some alien source.

Wishing to include in the survey some of the people of mid-Java I visited two villages near Cheribon on the North Shore:

At Gebongelir, 50 Javanese were treated, and a total of 2339 hookworms were obtained from them; of these 308 were $A$. duodenale the remainder being $N$. americanus, the ancylostome index being $13 \cdot 1$.

At Kalimaro, a village near by, 5140 hookworms were obtained from 24 persons; 332 were $A$. duodenale and the remainder were $N$. americanus, an ancylostome index of $6 \cdot 2$.

In the dessa of Kebasekan near Keboemen, not far from Djokjakarta (mid-Java), 25 persons yielded 4082 hookworms, the percentage of $A$. duodenale being $5 \cdot 4$.

From Krakal and Karangsari, villages in the same district, 28 Javanese yielded 10,861 hookworms of which 770 were $A$. duodenale; the ancylostome index being $7 \cdot 0 \%$.

The distribution of $A$. duodenale and $N$. americanus in Java and the neighbouring islands is well displayed in an analysis of the results of the worm findings among the prisoners in the jail in Batavia.

In this jail there are no opportunities for acquiring new hookworm infestation. Food is dispensed in a pasteurized or sterilized state while still warm. The sanitary arrangements while primitive I think effectually prevent hookworm infestation.

Confirmatory of this is the fact that of 118 men treated who had been in the jail for periods up to seven years or more, the average number per man was found to diminish with each succeeding year of imprisonment. This is inter- 
preted as meaning that the older worms die and are expelled, while there is no re-infestation or new infestation to make up this loss.

The people living in the kampongs round about outside the prison have; as we have seen, an ancylostome index of $0.88 \%$.

Within the jail compound the index is $9.2 \%$ from a total count of 8638 worms derived from 118 prisoners. This indicates that the prisoners bring their hookworms in with them and do not derive them directly or indirectly from the kampong people outside the jail through polluted water or food. We are confirmed in this view on an analysis of the findings, after separating the men into groups based on the part of the Netherlands Indies they came from.

Thus there were two prisoners giving their place of origin as Batavia or the Preanger, that is, West Java. The total worm count was 130 and the ancylostome index was 0.76 which is a West Java index.

There were nine prisoners from mid or East Java. The total worm count was 755 with an ancylostome index of $7.5 \%$-a mid-Java index.

Taking up the prisoners from Sumatra and other islands of the Netherlands Indies the index of each place may be ascertained from the prisoners and their respective differences noted.

Madura. This small island almost touches the eastern end of Java. There were 16 Madurese prisoners from whom 1263 hookworms were obtained; the ancylostome index was $13.7 \%$.

Bali. This interesting island, where the Hindu religious influence is still paramount, yielded five prisoners; the worm count was 348 and the ancylostome index $4.0 \%$.

Lombok, a neighbouring island, with 4 prisoners and a total worm count of 479 , gave an ancylostome index of $3.3 \%$.

Timor. This island, with four prisoners and a worm count of 100, gave an ancylostome index of $62.0 \%$.

Sumatra supplied 12 prisoners. The total worm count was 919 of which only 7 worms were $A$. duodenale, the ancylostome index being $0.9 \%$. Thus the index of Sumatra resembles that of the people of the adjoining portion of West Java and the Malay Peninsula in contra-distinction to that of the people of mid and East Java and the chain of islands extending towards Timor.

(There were two prisoners who had worm formulas resembling that of the Chinese. One of these, a Madras Tamil, had lived five years close to Chinese lines. The ancylostome index of these two men (38 worms) was $65 \%$. It is evident that they were infested from Chinese sources.)

Celebes. This island lies to the north of Timor and to the west of Borneo.

It supplied four prisoners yielding 523 hookworms, all $N$. americanus, the ancylostome index therefore being nil and representing what we may call the primitive Malay species formula.

This completes the data, highly interesting and important as they are in respect to the indices of the autochthonous population of Indonesia. 
Unfortunately there were no Malays from Borneo, Flores or Sumbava in our treatment groups, but the evidence as it stands, points distinctly to the supposition that the Malay people living in Sumatra (their ancient home?), Malay Peninsula, Java, Celebes and all the other islands of Indonesia were originally infested with $N$. americanus whilst $A$. duodenale became superimposed upon this infection in certain localities and islands through the migration thither of an alien ethnic stock or stocks infested with a much higher percentage of $A$. duodenale than that harboured by the autochthones.

From evidence to be presented there can be no doubt but that $A$. duodenale was introduced into Indonesia from the continent of Asia and in sufficiently large numbers to have become well implanted in the people and soil of mid and East Java and of Madura, Lombok, Timor and Bali as well.

What was the ethnic source of the migrants?

It was almost certainly from some region north of about $20^{\circ} \mathrm{N}$. latitude and may have been North Indian, that is from above the delta of the Ganges or thereabouts, Upper Burmah or Assam or it may have been from China.

Regular commercial relations had been maintained between India and Java since about 700 B.o., according to Oldham ${ }^{1}$. Arab and Chinese merchants have been coming to Indonesia for centuries and from these three sources the soil of Indonesia undoubtedly has been seeded with $A$. duodenale.

But to account for the high ancylostome index encountered in mid and East Java, Madura, Lombok and Timor we must assume the migration of larger numbers than would be represented by a few traders and sailors.

A volume of people corresponding to the respective numbers of the two species of hookworms in the ancylostome index has been necessary to produce the index as we find it.

That is to say, a thousand migrants with an ancylostome index of $75 \%$ when mixed with a Malay population eight times as large with an ancylostome index of nil will in time yield a mixed population with an ancylostome index of $8.3 \%$.

Buddhism is said to have reached the Indian Archipelago about 223 B.c. and there are Javan traditions that about 300 B.c. thousands of families from N.W. India and from the Kling coast were established in Java.

Java and possibly other islands in Indonesia were subjected to Hindu domination for 14 centuries or up to the 15th century A.D. The temples date from about 600 A.D. This was followed by a Mohammedan invasion. Portions of Indonesia undoubtedly became seeded with $A$. duodenale at this time.

It seems probable that the present ancylostome formula of the midJavanese resulted from this Hindu invasion, for the high ancylostome index is found in those districts in Java where the Hindu culture, as evidenced by the presence of temples or their ruins, was most intense, that is to say in mid and East Java.

1 Oldham (1905), The Serpent and the Sun, London. 
There are no chandis in West Java and but few ancylostomes there. In the Preanger they ( $A$. duodenale) are absent.

Beneath the cult of Mohammedanism in Indonesia there exists the remnants of Buddhism and Brahmanism. I have seen Javanese women who were nominally moslems actually worshipping in the ruins of a Brahman templea Hindu God. Underneath Brahmanism there yet lurks a pretty lively animistic cult, for the "hantu" or ghost possesses considerable influence in Malay households. Malay fishermen, at any rate in mid-Java, still attempt to propitiate by offerings of food the spirit which they believe presides over the destinies of fish and of fishermen, and thus modify the proverbial fishermen's luck.

Mohammedanism, Buddhism and Hinduism as well as Christianity have come to Indonesia from without.

It is possible that these cults in turn have been superimposed upon a preexisting animistic cult or cults also due to outside agencies.

Perry ${ }^{1}$ has called attention to the occurrence of stone monuments, dolmens, dissoliths, alignments and menhirs in Indonesia, notably in the Timor region, which bear certain resemblances to megalithic structures found in Burmah and Assam. He infers that the use of stone was not indigenous but was introduced from without to various parts of Indonesia. The new comers also introduced metal working, terraced irrigation and rice culture. These stone working migrants may have come from Burmah or Assam².

Whoever they were or at whatever period they made their appearance, if they contributed to the implantation of the ancylostome formula of the Timorese etc., it will be evident that they came from north of about $20^{\circ} \mathrm{N}$. latitude.

This belief in the source of $A$. duodenale is based on information derived from worm findings among North Indians, Chinese and Japanese.

With regard to North Indians the information comes from two sources, North Indians examined in (a) the Malay States and (b) Fiji.

\section{North Indians in the Federated Malay States.}

These are represented by Sikh and Mohammedan Police from the Punjab. Some of these men had lived in the Federated Malay States ten or more years and their native or natural formula had possibly undergone some changes due to infection derived from Tamil, Malay and Chinese sources; however if we take only those men who had lived in the Federated Malay States ten years and under, there are 7 cases with a total of 41 hookworms, 21 of which were $A$. duodenale or an ancylostome index of $51.2 \%$. A second group from among hospital patients was made up of Sikhs and Bengalis, 8 persons, with a total of 222 hookworms of which 71 were $A$. duodenale or an ancylostome index of $32 \%$.

\footnotetext{
1 Perry (1918), The Megalithic Oulture of Indonesia, Manchester.

2 There is however a trilithon at Haamonga, Tonga, which, according to tradition, was built by Polynesians (Samoans).
} 
North Indians in Fiji.

Additional data and probably of greater value were obtained in Fiji from indentured and free coolies that had come directly from Calcutta. That is to say, they had embarked at Calcutta having been recruited from various places, for the most part north of $20^{\circ} \mathrm{N}$. latitude-Central United and North West Provinces and speaking Hindustani-not Tamil or Telegu.

The information is of great value for there are no Chinese or other ancylostome bearing people on the island to complicate the species formula.

Thirty-four North Indians that had been brought out under indenture and had worked in the plantations five years and under were found to harbour 2480 hookworms, of which 684 were $A$. duodenale and the remainder $N$. americanus, the gross ancylostome index being $27.5 \%$. table.

The individual percentages vary from nil to 93 as is seen in the following North Indians, Fiji. Years resident in Fiji.

$\overbrace{\text { A. duod. Necat. }}^{1 \text { year }} \overbrace{\text { A.duod. Necat. }}^{2 \text { years }} \overbrace{\text { A. duod. Necat. }}^{3 \text { years }} \overbrace{\text { A. duod. Necat. }}^{4 \text { years }} \overbrace{\text { A. duod. }}^{5 \text { Necat. }}$

$\begin{array}{rrrrrrrrrr}33 & 11 & 51 & 5 & 31 & 17 & 9 & 17 & 8 & 27 \\ 21 & 197 & 3 & 38 & 28 & 98 & 19 & 83 & 47 & 74 \\ 30 & 20 & 56 & 36 & & & 4 & 29 & 53 & 347 \\ 1 & 6 & 24 & 247 & & & 29 & 64 & & \\ & & 31 & 24 & & & 8 & 16 & & \\ & & 5 & 6 & & & 0 & 17 & & \\ & & 17 & 25 & & & 1 & 1 & \\ & 5 & 2 & & & 39 & 3 & \\ & 15 & 3 & & & 3 & 20 & \\ & 23 & 8 & & & & & \\ & 43 & 101 & & & & & \\ & 16 & 7 & & & & & & \\ & 20 & 83 & & & & & & \\ & 5 & 90 & & & & & & \\ & 1 & 58 & & & & & \end{array}$

The free Indians or those who elected to remain in Fiji after their indenture had expired, were found after 7 to 14 years of residence to have lost a good many of their A. duodenale but to have become severely infected with Necator - the hookworm of the Fijians and of the country.

Among 35 Free North Indians the ancylostome index was found to be only $4.2 \%$-a striking illustration of the tendency of the index of the immigrants to approach that of the autochthones.

Chinese.

Other Astatios from North of $20^{\circ} \mathrm{N}$. Latitude.

The Chinese fall into two groups (a) those born in China who came to the Federated Malay States or Java as adults and $(b)$ those born in Indonesia.

Chinese immigrants to Indonesia come from the Southern Provinces and 
are known as Khehs, Cantonese, Hylams (Hainan) and Hockians. The new comers or "Sinkehs" of course bring with them typical worm formulas of their native country.

"Lowkehs" or men who have returned to Indonesia after a previous visit possess formulas altered possibly by previous residence.

It is not always possible to learn with accuracy a man's previous residence, for the Oriental is very guarded in replying to questions and may have reasons for wishing to appear as a new comer, this being particularly the case in Chinese who had been banished for crime.

At St John's Island, Singapore, we treated 46 "Sinkehs" and obtained 1241 hookworms of which 420 were $A$. duodenale and 821 were $N$. americanus, thus the ancylostome index was $33 \cdot 8$. In this group there were ten cases of pure Necator infection yielding altogether 148 worms. $36.9 \%$ of the men had indices falling within the group index of $33 \cdot 8$.

Among the patients treated at the District Hospital, Kuala Lumpur, there were 79 Chinese who yielded 5191. hookworms, of these 1994 were A. duodenale and $3197 \mathrm{~N}$. americanus, the ancylostome index being 38.4 .

In this group there were 12 cases of pure Necator infection and 37 other cases whose indices were below the average for the whole group. The men had lived in the Federated Malay States for periods up to 20 years and possibly to some slight extent represent infection derived from other races. On the other hand the index is very close to that of Sinkehs and the index 38.4 or 33.8 in all likelihood represents a border line or frontier index, where the species overlap.

In five fatal cases of hookworm infection the ancylostome index was $86.1 \%$, there having been found $3779 \mathrm{~A}$. duodenale and $698 \mathrm{~N}$. americanus.

\section{Chinese born in Indonesia.}

Some data were obtained on the index of Chinese born in Indonesia, few cases it is true but very interesting as showing how children of the foreigners take up the worm index of the natives of the country.

Two Straits born Chinese were examined in Kuala Lumpur. One was of the first generation, the other of the second generation born in the Malay Peninsula. 72 worms were obtained from these young men, all Necator, the ancylostome index being nil.

Among the Chinese treated in the Batavia jail there were two born in Java. The man who was born in West Java had 123 hookworms, one of which was $A$. duodenale, a percentage of $0 \cdot 8$, which is a West Java index. The other who was born in mid-Java had 57 hookworms of which 11 were $A$. duodenale, giving a percentage of $19 \cdot 3$ which is a mid-Java index. Rather a striking illustration of the effect of regional soil in determining the species formula.

The physical resemblances between Malays and Chinese are very strong indeed. Wallace observed this in adults and even after having become 
thoroughly familiar with the two races, I was at times unable to tell which of two sunburnt boys was the Malay and which the Chinese.

Yet close as the physical resemblances such as physiognomy, physique and cranial indices are, the helminthological testimony indicates that the Malays as a whole are no recent migrant stock from Southern China.

The Malays are not Chinese who have moved southward towards the equator and mixed with a dark skinned race, for the worm formula of the Malays is distinct from that of the Chinese. If the Chinese had migrated into Indonesia in hordes the ancylostome index of the Malays would approach that of the Chinese but this it does not do.

Some Malays may have moved northward and added their complement of Necator to an ancylostome-bearing Chinese stock, for the Chinese of South China to-day carry large numbers of Necator with their ancylostomes.

The presence of $A$. duodenale in mid and East Java, Madura, Lombok and Timor is not due to the presence of the relatively few Chinese coolies, traders or shopkeepers there, for the native population greatly outnumbers the Chinese. As a result we see the Chinese that are born in Java taking on the native index.

On the other hand where large numbers of $A$. duodenale carriers are present, as among the North Indians in Fiji, they are perceptibly infecting the native Fijians, just as we may suppose the Hindus or Burmese may have infected the Javanese of mid-Java centuries ago.

A small group of Japanese women, four in number, who had lived in the Federated Malay States three years and under were found to harbour 61 hookworms of which 19 were $A$. duodenale, giving an ancylostome index of $31 \cdot 1$. The index of the Japanese therefore resembles that of the Chinese and North Indians and is in marked contrast with the primitive index of people south of $20^{\circ} \mathrm{N}$. latitude, that is, the Tamils, Malabaris and Malays.

Thus we see that there is a solid zone lying to the north within which the people have high ancylostome indices. It is from people in this more northerly zone that $A$. duodenale was introduced into mid and East Java and neighbouring islands.

\section{South Indians.}

Tamils, Malabaris and other Davidian natives of Southern India entering the Port Swettenham Quarantine Station were found to possess a uniformly low ancylostome index.

A series of treatments were carried out by Hacker and Barber on South Indian coolies, Tamils and Malabaris at Port Swettenham Quarantine Station.

From three squads, 31 persons, 4363 hookworms were obtained, 89 of which were $A$. duodenale giving an ancylostome index of $2 \cdot 0$.

This low ancylostome index among South Indians was encountered with great uniformity and serves to differentiate the North from the South Indians.

Twenty-five Malabaris that had lived in the Federated Malay States but 
a few months yielded 3491 hookworms of which 30 only were $A$. duodenale and the remainder $N$. americanus, an ancylostome index of 0.86 .

A group of 35 Tamil coolies engaged in road repairing in Kuala Lumpur were found to be harbouring 2870 hookworms of which 59 were $A$. duodenale, the remainder $N$. americanus, the percentage of ancylostomes being $2 \cdot 0$.

\section{Polynesia.}

Fijians represent a mixture of two stocks, Melanesian and Polynesian.

The typical Melanesian is exemplified by the Papuan, while the Polynesian is represented by the Tongan or Samoan.

Fusion of the two stocks is going on to-day in Fiji. With the object of learning what the species formula of the autochthonous Fiji population was, the remote and rather inaccessible village of Nasoqo in the mountains at the head waters of the Rewa River was visited and a group of 15 persons treated.

Among 546 hookworms obtained not a single $A$. duodenale was encountered, the ancylostome index being nil (a few $A$. ceylanicum were found as in the mountain villages of Java but these are derived from dogs and have no bearing on the $A$. duodenale index).

The worm counts made on the town dwelling Fijians (village of Nausori) confirm the findings at Nasoqo, but, as we have seen, they show evidences of contaminative infection by $A$. duodenale from North Indian sources, that is, from plantation and factory coolies working and living in the same village.

Until further and more detailed survey work is done in Polynesia we may assume that the primitive ancylostome index in this region is nil.

This observation at Nasoqo is of the greatest value, for it was made on a pure uncontaminated population of two fused South Sea ethnic stocks. Chinese, Japanese, Portuguese and East Indian immigrations have been for several years altering the primitive index of South Sea Islanders in the towns and villages near plantations.

The absence of $A$. duodenale in Fiji among uncontaminated autochthones indicates that races carrying $A$. duodenale as the Egyptians, Chinese, Burmese, Japanese and North Indians have never colonized there, and it shows that the Fijians, wherever their stock originally came from, did not come from north of $20^{\circ} \mathrm{N}$. latitude and have never been in contact with people from those latitudes.

This is a matter of considerable interest in view of the probably erroneous opinion held by some that the Polynesians originated in northern Africa or Asia and that during their migrations southward they sojourned in Fiji.

Additional surveys are urgently needed in Polynesia before we can speak confidently in this matter.

To one who has been intimately acquainted with Malays and Javanese and has seen something of the Papuans, Solomon Islanders, Fijians, Tongans, Samoans and Maoris there is beyond certain linguistic similarities nothing to 
suggèst Malayan immigration to Polynesia, and these similarities may otherwise be explained.

\section{FURTHER OBSERVATIONS AND CONCLUSIONS.}

The hookworms harboured by a people depend on geographical, racial and climatic conditions and circumstances.

A people can only harbour the worm species which have been existing as embryos in the soil of their immediate environment.

The hookworms harboured by a person may disclose the influences to which he has been subjected in another environment.

The relative number and species of hookworms will sometimes furnish indications as to the ethnic origin of a people about whose history there is no record.

There has been a migration of rather large numbers of Asiatic people into parts of Indonesia.

These people came from north of $20^{\circ} \mathrm{N}$. latitude, probably India or Burmah, and colonized in fairly large numbers in mid and East Java, Bali, Timor, Lombok and Madura as is evidenced by the hookworm species formula of the people now resident there. Other parts of Indonesia may have been visited as no doubt they were, but not by people in sufficiently large numbers to affect appreciably the normal formula of Indonesian people.

This Asiatic emigration did not extend to Polynesia, Fiji and Tonga for there are no helminthological evidences of it.

Whatever migration to the South Seas occurred, if any, it must have taken place by people from south of $20^{\circ} \mathrm{N}$. latitude, that is, from Madras, or Malay Peninsula, Sumatra or other parts of Indonesia or previous to the Asiatic colonization of Java and Bali. That is to say by a people with an ancylostome index amounting to nil.

The presence of pure cultures or of relatively pure cultures of Necator in natives of Asia or Africa indicates that their hosts belong in the south rather than to the north, for the primitive distribution of Agchylostoma duodenale seems to have been limited to regions north of $20^{\circ} \mathrm{N}$. latitude, while $N$. americanus was distributed south of this line.

$A$. duodenale may have been conveyed to or from the Orient along the old trade routes. But there are no evidences that Necator was introduced into Southern Europe from the east or into Egypt from South Africa for Necator is not found in Southern Europe or in Egypt. At any rate this species does not seem to be distributed to the latter places.

Careful surveys àre necessary here as elsewhere, for it must be remembered that $N$. americanus was for years overlooked in India by British, Dutch and French doctors, although the species exists there in enormous numbers. Practically every East Indian over 14 years of age living north of Calcutta being infected with both species.

If certain tribes in America are found to be infected with A. duodenale as 
well as Necator this will suggest their having come to this continent by way of the sea from those countries in Asia where A. duodenale and Necator are found to be infecting the natives, i.e. Japan and China.

A careful hookworm survey of existing Indian tribes may disclose the presence of more than one primitive stock. In other words: $(a)$ a stock free from hookworms derived from Asiatic trans-Behring ancestors, $(b)$ a stock harbouring both $A$. duodenale and Necator derived from Asiatic trans-Pacific ancestors, and $(c)$ a stock with a pure Necator infection derived from Polynesian or Indonesian trans-Pacific ancestors.

If the Indian races or some of them living in regions unvisited by strangers are found to be free from hookworms this would furnish some grounds for supposing that the races in question had been derived from ancestors who had crossed from Asia by way of Behring Straits.

Surveys of all ethnic groups of people are urgently required before there occurs that mixing of stocks which will efface the individualities of species formulas.

Surveys are particularly desired in America among various North, South and Central American tribes, in Asia (subtropical), the Philippines, in Melanesia, Micronesia, Polynesia, Australia and in Madagascar and Easter Island. 